\title{
Strategi Kepala Sekolah Dalam Meningkatkan Standar Mutu Pendidikan di Tingkat Dasar
}

\author{
Nining Syamsi Komariah \\ Universitas Islam Negeri Sultan Maulana Hasanudin Banten, Serang, Indonesia \\ *Corresponding author: nining.komariah@uinbanten.ac.id
}

\begin{abstract}
Strategy is a plan that will be done in order that all the works can get expected satisfied results. Formal institutions should have strategies, professional resources as the answer, the quality human that is able to develop themselves and their institution. The presence of the basic level who have not got training from the relevant institutions, much less achievement raises National Standard 8, so the input and output less in balance, this study focused on strategies of the basic level of private for improving the standard of quality of education. The purpose of this study was to describe the strategies adopted by the principal in the education quality standards at the primary level. The method used in this research is a qualitative approach, collective data through library research, observation, interview. The conclusions in this study showed that the Strategies of Head of Private Sekolah Aliyah to improve the quality of education is have a work program of short-term, medium and long term that neatly documented
\end{abstract}

Keywords: quality standards; strategy

\section{ABSTRAK}

Strategi merupakan rencana yang akan dilakukan agar semua pekerjaan mendapatkan hasil yang memuaskan sesuai dengan apa yang diharapkan. Seyogyanya lembaga formal wajib memiliki strategi yang jitu,. sumber daya profesional sebagai jawabannya,manusia yang berkualitas yang mampu mengembangkan diri dan lembaga. Adanya kepala sekolah tingkat dasar yang belum mendapatkan pelatihan dari lembaga terkait, banyak menimbulkan kurang tercapainya 8 Standar Nasional, sehingga input dan output kurang seimbang.Penelitian ini di fokuskannya pada strategi kepala sekolah tingkat dasar dalam meningkatkan standar mutu pendidikan. Tujuan penelitian ini adalah mendeskripsikan strategi yang dilakukan kepala sekolah dalam standar mutu pendidikan di tingkat dasar. Metode yang digunakan dalam penelitian ini adalah dengan menerapkan pendekatan kualitatif, tehnik pengumpulan datanya melalui studi kepustakaan, observasi, interview. Simpulan dari penelitian ini menunjukan bahwa para kepala sekolah tingkat dasar dalam strategi untuk meningkatkan standar mutu pendidikan dengan memilki program kerja jangka pendek, menengah dan jangka panjang yang terdokumentasikan secara rapih dan dapat dipertanggungjawabkan.

Kata Kunci: standar mutu; strategi

\section{Pendahuluan}

Strategi merupakan rencana yang akan dilakukan agar semua pekerjaann mendapatkan hasil yang memuaskan sesuai dengan apa yang diharapkan. Seyogyanya lembaga formal wajib memilki strategi yang jitu, karenanya lembaga pendidikan memerlukan sumber daya manusia yang profesional agar dapat menjalankan fungsinya menuju pencapaian tujuan yang telah ditargetkan. Sekolah dasar adalah salah satu lembaga pendidikan di bawah naungan Kementrian Agama, termasuk lembaga pendidikan formal. Sekolah dasar selaku pimpinan dalam institusi pendidikan Islam ini diharapkan dapat menjalankan tugas dengan baik dan mampu mengembangkan diri bersama mitra kerjanya untuk mencapai kemajuan sekolah (Abdul Munir,2010). Sebab bagaimana pun jika sekolah tidak memiliki strategi bagai mobil tanpa bensin, bagai sayur tanpa garam artinya hambar. Di sisi lain, untuk dapat keluar sebagai pemenang dalam era yang penuh persaingan ini kata kuncinya adalah sumber daya 
manusia yang berkualitas. Karena itu pendidikan menjadi sebuah keniscahyaan yang tidak dapat ditawar-tawar lagi, kuantitas dan kualitas pendidikan harus diprioritaskan secara seimbang dan mencakup semua hal diantaranya sarana dan prasarana, media, tenaga kependidikan, dan pembiayaan pendidikan (Junaidi, 2011).

Kepala Sekolah yang ideal mampu mensinergikan kemampuan manajemen dan kemampuan kepemimpinan secara simultan. Lebih lanjut Banun, dkk (2016) menyatakan bahwa seorang pimpinan selayaknya dapat mengarahkan dan mempengaruhi semua potensi dan sumber daya yang dimiliki untuk kepentingan organisasi. Karena Allah sangat mencintai orang yang jika melaksanakan sesuatu pekerjaan, dilakukan secara itqon (tepat, terarah, jelas dan tuntas) (Sulistiorini, 2009). Pada hakekatnya manusia adalah mahluk sosial alias zoon politicon, yang secara naluriyah membutuhkan bergaul dan membutuhkan manusia lain, yang dalam prosesnya mereka membantu kelompok, masyarakat, berbangsa bernegara, yang pada gilirannya membutuhkan seorang pemimpin untuk mengatur, membangun dan memajukan masyarakat.

Dengan demikian aktivitas kepala sekolah yang berkaitan dengan tugas manajerial sebagai berikut menyusun pembelajaran, mengelola kesiswaan, mengelola sarana dan prasarana, mengelola personal sekolah, mengelola keuangan sekolah, mengelola hubungan sekolah dan masyarakat, mengelola administrasi sekolah, mengelola sistem informasi sekolah, mengevaluasi program sekolah, memimpin sekolah. Fitrah (2017) mengemukakan sekolah itu berkualitas atau tidak sangat bergantung pada pola kepemimpinan kepala sekolah, karena dialah pimpinan tertinggi di sekolah, dan dialah yang bisa mengambil keputusan dalam segala hal. Hal yang lebih urgen adalah seorang kepala sekolah harus memiliki sekurang kurangnya 5 kompetensi diantaranya adalahh kompetensi kepribadian,Kompetensi manajerial, kompetensi kewirausahaan, kompetensi supervisor, kompetensi social (Suhardiman, 2012).

Tak dapat disangkal lagi bahwa menyelesaikan masalah perlu adanya strategi dan kepemimpinan yang profesional, khususnya di Sekolah, agar dapat menyentuh dan mempengaruhi dan bahkan dapat merasuki seluruh aspek kehidupan manusia layaknya darah dan raga. Bahwa manusia dapat mengenali kekurangan dan kelebihan diri dan profesionalisme juga menunjukan cara-cara yang lebih efektif dan efesien dalam pelaksanaan suatu pekerjaan, bahkan dapat mengurangi hambatan-hambatan dalam rangka mencapaian suatu tujuan (Sulistiorini, 2009). Penelitian ini difokuskan pada ditemukannya model konseptual strategi kepala sekolah dalam meningkatkan standar mutu pendidikan. Tujuan penelitian ini adalah mendeskripsikan strategi yang dilakukan kepala sekolah dalam standar mutu pendidikan di tingkat dasar.

\section{Metode Penelitian}

Penelitian ini menggunakan pendekatan kualitatif untuk mendeskripsikan kegiatan yang dilaksanakan secara kaffah agar memperoleh akuratisasi dalam data, penulis berusaha semaksimal mungkin untuk mengolah data seoriginal mungkin sesuai dengan data yang diperoleh di lapangan baik berupa tulisan maupun berupa informasi lain. Pendekatan kualitatif berusaha mengungkap berbagai keunikan yang terdapat dalam individu, kelompok, masyarakat, dan/atau organisasi dalam kehidupan sehari-hari secara menyeluruh, rinci, dalam, dan dapat dipertanggungjawabkan secara ilmiah. Pendekatam kualitatif atau disebut juga pendekatan naturalistik adalah penelitian yang menjawab permasalahan penelitian yang 
memerlukan mpemahaman secra mendalam dan menyeluruh terhadap obyek yang diteliti ,untuk menghasilkan kesimpulan kesimpulan penelitian dalam kontek waktu dan situasi yang bersangkutan (Satori dan Komariah, 2010).

Metode kualitatif sebagai prosedur penelitian yang menghasilkan data deskriptif berupa kata-kata tulisan dari orang yang diamati. Selain itu metode penelitian kualitatif adalah metode penelitian yang berlandaskan pada filsafat postpositivisme, yang digunakan untuk meneliti pada kondisi obyek yang alamiah, dimana peneliti adalah sebagai instrumen kunci, dan teknik pengumpulan datanya dilakukan secara triangulasi (gabungan) analisis data bersifat induktif/kualitatif, dan hasil penelitian kualitatif/lebih menekankan pada makna daripada gerenalisasi.

Adapun jenis data yang penulis himpun adalah primer dan sekunder. Jenis data primer adalah data awal diantaranya mengenai strategi tingkat dasar dalam upaya meningkatkan mutu pendidikan. Sedangkan yang dimaksud dengan data sekunder adalah pemangku/pemerintah pada lembaga terkait dengan pendidikan, para pemilik yayasan, para komite sekolah, tingkat dasar, dewan guru, tenaga kependidikan dan siswa di tingkat dasar, juga sejumlah tingkat dasar dan sebagai penyempurna dalam penelitian ini didukung dengan berbagai data yang akurat.

\section{Hasil dan Pembahasan}

Perencanaan program yang diselenggarakan oleh lembaga-lembaga pendidikan harus mencerminkan adanya visi, misi, dan merumuskan tujuan serta mengembangkannya yang dinyatakan dalam RKM yang disetujui oleh dewan pendidik dan komite sekolah. Serta dituangkan dalam dokumen yang mudah dibaca oleh pihak-pihak yang terkait. Memiliki visi misi yang baik, rencana kerja jangka pendek, menengah dan jangka panjang. Yang memuat ketentuan yang jelas mengenai kesiswaan, kurikulum, pendidik dan tenaga kependidikan, sarana dan prasarana, keuangan dan pembiayaan, budaya lingkungan, peran masyarakat dan rencana lain yang mengarah pada peningkatan mutu dan pengembangan mutu. Rencana kerja paling tidak dapat merumuskan kedalam pedoman dasar, sekolah yang mengatur berbagai aspek pengelolaan secara tertulis. Pedoman pengelolaan sekolah meliputi kurikulum KTSP/KURTILAS, kalender pendidikan, struktur organisasi, pembiayaan tugas diantara guru, pembagian tugas diantara tenaga kependidikan, peraturan akademik, tata tertib sekolah, kode etik sekolah, biaya operasional sekolah (Mulyasa, 2015).

Adapun strategi pengelolaan program dapat ditempuh antara lain dengan langkahlangkah sebagai berikut. Memberdayakan komite sekolah/majelis sekolah dalam peningkatan mutu pembelajaran di sekolah, Unsur pemerintah Kabupaten/Kota dalam hal ini instansi yang terkait antara lain Dinas Pendidikan, Badan Perencanaan Kabupaten/Kota, Dewan Pendidikan Kabupaten/Kota terutama membantu dalam mengkoordinasikan dan membuat jaringan kerja (akses) ke dalam siklus kegiatan pemerintahan dan pembangunan pada umumnya dalam bidang pendidikan, Memberdayakan tenaga kependidikan, baik tenaga pengajar (guru), kepala sekolah, petugas bimbingan dan penyuluhan (BP) maupun staf kantor, pejabat-pejabat di tingkat kecamatan, unsur komite sekolah tentang Manajemen Berbasis Sekolah, pembelajaran yang bermutu dan peran serta masyarakat, Mengadakan pelatihan dan pendampingan sistematis bagi para kepala sekolah, guru, unsur komite sekolah pada pelaksanaan peningkatan mutu pembelajaran, Melakukan supervisi dan monitoring yang 
sistematis dan konsisten terhadap pelaksanaan kegiatan pembelajaran di sekolah agar diketahui berbagai kendala dan masalah yang dihadapi, serta segera dapat diberikan solusi/pemecahan masalah yang diperlukan, Mengelola kegiatan yang bersifat bantuan langsung bagi setiap sekolah untuk peningkatan mutu pembelajaran, Rehabilitasi/Pembangunan sarana dan prasarana Pendidikan, dengan membentuk Tim yang sifatnya khusus untuk menangani dan sekaligus melakukan dukungan dan pengawasan terhadap tim bentukan sebagai pelaksana kegiatan tersebut (Fathurohman, 2012).

Dalam tinjauan lain langkah langkah peningkatan mutu pendidikan di sekolah dapat dilaksanakan sebagai berikut; Bechmarking yaitu kegiatan untuk menerapkan standar baik proses maupun hasil yang akan dicapai dalam suatu priode tertentu, Quality Assurance yang bersifat proses oriented proses yang sedang dilaksanakan sesuai dengan standar dan prosedur yang telah ditetapkan sehingga sesuai sehingga efektif, Quality Control suatu sistem untuk mendeteksi penyimpangan qualitas autput yang tidak sesuai dengan standar, School Review yaitu proses yang mengharuskan seluruh komponen lembaga untuk bekerja sama dengan berbagai pihak yang memiliki keterkaitan misalnya orang tua,tenaga profesional pemerintah dan sebagainya, dalam hal ini harapannya dapat mengungkapkan kelemahan kelemahan, kekuatan kekuatan, dan memberikan rekomendasi untuk penyusunan perencanaan strategis pengembangan pendidikan di masa yang akan datang.

Program Kepala Sekolah harus terencana secara kongkrit dan terukur secara nyata di lapangan, dapat mendeteksi faktor pendukung juga faktor penghambatnya. Maka strategi Kepala Sekolah dalam meningkatkan mutu pendidikan dapat dirasakan oleh Masyarakat Sekolah khususnya dan Masyarakat pada umumnya. Bagaimanapun tahapan tahapan Perencanaan program pendidikan harus mendefnisikan permasalahan perencanaan pendidikan. Menganalisis bidang telaah permasalahan perencanaan. Mengkonsepsikan dan merancang rencana. Menentukan rencana, mengevaluasi serta mengimplementasikan dan umpan balik.

Setelah melakukan penyusunan program jangka pendek jangka menengah dan jangka panjang yang tertulis dalam buku program sekolah, maka selanjutnya mengimplementasikan program kepala sekolah untuk mencapai 8 standar pendidikan, dari mulai standar isi, standar proses, standar sarana dan pasarana, standar ketenagaan ,standar kelulusan, standar penilaian, standar pembiayaan dan standar pengelolaan.

Adanya peningkatkan program kepala sekolah dalam standar mutu pendidikan, peningkatkan perencanaan program kepala sekolah dapat di lihat dari hasil input dan output para tenaga pendidik dan Kependidikan serta siswa yang bersemangat dalam menjalankan tugas dan kewajibannya masing masing dan dapat di lihat dari prestasi prestasi yang di raih oleh lembaga tersebut. Hakikatnya strategi kepala sekolah tingkat dasar dapat menentukan arah kebijakan Pemerintah untuk membentuk masyarakat memiliki spiritual tinggi, cerdas dalam berfikir ,cerdas dalam bertindak serta dapat meminimalisir hambatan hambatan yang ada di lapangan.

Pengendalian Kepala Sekolah dalam meningkatkan mutu pendidikan. menerapkan disiplin yang kuat secara bersama sama, mengadakan pengawasan yang melekat secara simultan. Memberikan penghargaan terhadap tenaga pendidik dan kependidikan bagi yang berprestasi serta memberikan teguran terhadap yangmelakukan pelanggaran. Kepala sekolah bersama sama meningkatkan empat kompetensi,kompetensi spiritual, kompetensi sosial, 
kompetensi ilmu pengetahuan dan kompetensi keterampilan dan strategi kepala sekolah dalam meningkatkan mutu pendidikan diantaranya adalah meningkatkan kualitas tenaga pendidik dan kependidikan dengan menyeimbangkan jasa yang harus diberikan kepada dewan guru, memfasilitasi kegiatan siswa untuk musabakoh dalam rangka pastabikul khoirot antara pelajar mulai tingkat kota ,kabupaten maupun provinsi, mengadakan seleksi ketika penerimaan siswa baru, selalu mengevaluasi kegiatan belajar mengajar dan kegiatan lainnya setiap minggu dan akhir bulan. Bekerja sama dengan wali murid,masyarakat dan lembaga terkait dalam dan luar negeri.

Adapun Faktor pendukung diantaranya adalah siswa siswi dari Sekolah nyaris tidak pernah terdengar tauran antara Sekolah maupun sekolah. Para dewan guru rata rata mengajar dengan penuh keikhlasan .dan jiwa sosial para pemilik yayasan tinggi. Terbantu dengan adanya sumbangan dari pemerintah seperti dana BSM (Bantuan Siswa Miskin) BOS (Bantuan operasional sekolah) walaupun masih relatif kecil. Kesadaran mayoritas wali murid tinggi untuk menitipkan putra putrinya di sekolah agar mendalami ilmu dan mengaflikasikan dalam kehidupan sehari hari. Siswa dapat mempelajari dua kurikulum sekaligus dari Diknas dan Jam mata pelajaran siswa siswi di sekolah lebih padat.

Faktor penghambat di sekolah sebagai berikut: Dana batuan BSM terbatas dan sangat kurang dari jumlah siswa miskin yang ada pada masing masing lembaga, Dana Bos dari pemerintah tidak tepat waktu datangnya serta masih minimalis. Nominalnya untuk ukuran persiswa dalam satu tahun, Banyaknya Tenaga pengajar di sekolah masih miss mact, Guru yang sudah di sertifikasi nyaris kekurangan jam mengajar, Guru guru honorer di sekolah jarang mendapatkan pelatihan terkait dengan pengembangan kependidikan, dari pemerintah, Siswa siswi di sekolah jarang mengikuti even even olah raga yang bersifat Nasional, Para pengajar di Sekolah jarang menggunakan teknologi IT dalam kegiatan belajar mengajarnya. Kecuali pengajar computer, Masih kurang menyebar ke sekolah sekolah buku kurtilas, Belum dibatasinya rekrutmen siswa masuk pada sekolah negeri baik maupun sehingga berkurangnya siswa masuk sekolah, Belum terrealisasi bintek kurtilas dan masih minimalis sosialisasi tentang kurtilas serta sarana dan prasarana untuk belajar masih kurang.

\section{Kesimpulan}

Strategi Kepala sekolah dalam upaya meningkatkan mutu pendidikan dapat disimpulkan sebagai berikut program yang tepat, tearah sesuai dengan visi, misi dan tujuan berupa RKS dan RABS yang terdokumenkan secara rapi dan dapat dipertanggungjawabkan dari mulai jangka pendek. jangka menengah, dan jangka panjang, dengan menggunakan strategi yang berbeda walaupun tujuannya sama yaitu mencerdaskan kehidupan bangsa. Adapun implementasi program yang dilakukan oleh seorang kepala sekolah dalam meningkatkan mutu sekolah diantaranya adalah; dengan merealisasikan 8 Standar Nasional Pendidikan dengan menggunakan manajemen strategi. Melaksanakan tupoksi kepala sekolah sebagai educator, manager, administrator dan supervisor. Meningkatkan keilmuan terkait dengan pengembangan sekolah. Menjalin kerja sama dengan pihak pihak yang menguntungkan dan tidak mengikat. Memperbanyak promosi di setiap kesempatan. Memperbanyak output dan outcome sesuai harapan masyarakat terkait. Serta meningkatkan prestasi siswa dari segi akademik maupun non akademik. 


\section{Daftar Pustaka}

Arikunto, S. (1998). Modul Evaluasi Program. Yogyakarta: FIP IKIP.

Banun, S, dkk. (2016). Strategi Kepala Sekolah Dalam Meningkatkan Mutu Pendidikan Pada SMP Negeri 2 Unggul Mesjid Raya Kabupaten Aceh Besar. Jurnal Administrasi Pendidikan. Vol 4 No.1. 137-147.

Fatah, S. (2002). Manajemen Mutu Pendidikan Berbasis Madrasah. Semarang: Pustaka Rizki Putra Fathurrohman, dkk. (2012). Implementasi Manajemen Mutu Pendidikan Islam. Yogyakarta: Teras Fitrah, M. (2017). Peran Kepala Sekolah Dalam Meningkatkan Mutu Pendidikan. Jurnal Penjaminan Mutu. Vol 3 No.1. 31-42

Hamalik, O. (2009). Dasar-Dasar Pengembangan Kurikikulum. Bandung: Remaja Rosdakarya Junaidi. (2011). Desain Pengembangn Mutu Madrasah. Jogyakarta: Teras Mulyasana. (2015). Pendidikan Bermutu dan Berdaya Saing. Bandung.

Saefullah. (2012). Manajemen Pendidikan Islam. Bandung: Pustaka Setia

Saton, D dan Komanah. Metodologi Penelitian Kualitatif. Bandung: Alfabeta. 2010.

Sugiono. (2011) Metode Penelitian Kuantitatif Kualitauf dan RED. Bandung, Alfabeta, cet ke:14

Sulistiyorini. (2009). Manajemen Pendidikan Islam, Konsep, Strategi, dan Aplikasi. Yogyakaita: Teras 